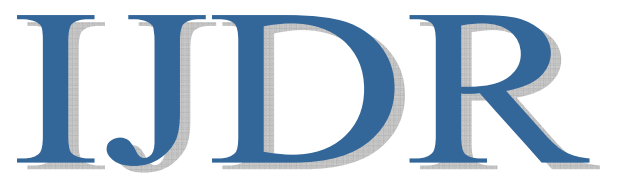

International Journal of Development Research

Vol. 10, Issue, 06, pp. 36832-36839, June, 2020

https://doi.org/10.37118/ijdr.19057.06.2020

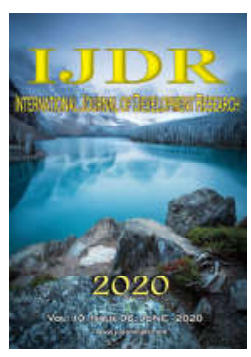

\title{
A INCLUSÃO COMO PROJETO DE EDUCAÇÃO E GARANTIA DE DIREITOS DA PESSOA COM DEFICIÊNCIA NAS SÉRIES INICIAIS DO ENSINO FUNDAMENTAL DAS ESCOLAS PÚBLICAS BRASILEIRAS
}

\author{
${ }^{*}$ Bianca Marinho de Souza, ${ }^{2}$ Joaquina Ianca dos Santos Miranda, ${ }^{3}$ Kátia Maria Barros de \\ Miranda and ${ }^{4}$ Luciano Tadeu Corrêa Medeiros
}

1,2,4Universidade Federal do Pará (UFPA)

3Secretaria Municipal de Educação-São Miguel do Guamá - Pará (SEMED)

\section{ARTICLE INFO}

\section{Article History:}

Received $17^{\text {th }}$ March, 2020

Received in revised form

$11^{\text {th }}$ April, 2020

Accepted $16^{\text {th }}$ May, 2020

Published online $29^{\text {th }}$ June, 2020

\section{Key words:}

Educação Pública. Inclusão,

Pessoas com Deficiência,

Garantia de direitos.

*Corresponding author:

Bianca Marinho de Souza

\begin{abstract}
O artigo trata do direito a Educação da Pessoa Com Deficiência e da inclusão desses sujeitos no sistema público de ensino brasileiro. O objetivo é analisar quais ações são aplicadas pela escola para a inclusão desses sujeitos nos estabelecimentos públicos de ensino e como esse projeto de inclusão se desenvolve no contexto escolar, visando efetivar a garantia do direito à educação desses alunos. O trabalho utilizou o método qualiquantitativo e foi realizado com base em análise de dados de uma pesquisa de campo realizada por alunos do curso de Pedagogia da Universidade Federal do Pará no segundo semestre do ano de 2018 em escolas da rede pública da região urbana de Belém - PA, Brasil -, juntamente com uma pesquisa de revisão bibliográfica de autores que tratam do tema. Os resultados apontam dificuldades para a efetivação da inclusão e manutenção da Pessoa Com Deficiência nas escolas públicas de Belém, devido à desestrutura física dos espaços, à impossibilidade de ações administrativas e Pedagógicas coordenadas e à falta de continuidade na formação docente nessas escolas, em virtude da lacuna causada pela ausencia de políticas públicas e educacionais por parte do Estado brasileiro que visem a garantia do direito àeducação e inclusão desses sujeitos no sistema público de ensino.
\end{abstract}

Copyright (C) 2020, Bianca Marinho de Souza et al. This is an open access article distributed under the Creative Commons Attribution License, which permits unrestricted use, distribution, and reproduction in any medium, provided the original work is properly cited.

Citation: Bianca Marinho de Souza, Joaquina Ianca dos Santos Miranda, Kátia Maria Barros de Miranda and Luciano Tadeu Corrêa Medeiros. “A inclusão como projeto de educação e garantia de direitos da pessoa com deficiência nas séries iniciais do ensino fundamental das escolas públicas Brasileiras", International Journal of Development Research, 10, 06, 36832-36839.

\section{INTRODUCTION}

A Educação Pública e universal é um direito adquirido que tem se estabelecido na realidade brasileira (BRASIL, 1996) como um dos pilares de democratização do ensino (FREIRE, 1980; LIBÂNEO, 2006) e, através dela, do ponto de vista social, político, pedagógico e também educativo, torna-se uma alternativa (FREIRE, 1996) para que a maior parcela de brasileiros tenha acesso à escolarização. Mesmo que alguns autores exerçam críticas sobre a sistematização e institucionalização do ensino, outra grande maioria defende esse formato educativo (FREIRE, 1980; LIBÂNEO, 2006), por reconhecer no mesmo a possibilidade de formação de um sujeito crítico e reflexivo (FREIRE, 1996) que possa atuar de forma consciente em meio ao sistema estabelecido (LIBÂNEO, 2006), fazendo com que a Escola, através de seu modelo educacional, consiga, em seus processos, ter um caráter libertador e promoter da emancipação e autonomia dos sujeitos (FREIRE, 1996).
Sabemos que, para além de uma concepção simplista de escola pública (LIBÂNEO, 2006), as Ciências da Educação reafirmam-na como elemento importante para o desenvolvimento não apenas no segmento cognitivo, mas nos parâmetros globais da composição dos sujeitos (FREIRE, 1980; LIBÂNEO, 2006), pois, em meio a ações de ensinoaprendizagem e de interação e socialização que envolvem os processos educativos, deve-se reconhecer que a Educação escolar é capaz de proporcionar o desenvolvimento humano global daqueles que se encontram dentro desse processo como alunos (BRASIL, 1996; LIBÂNEO, 2006). Esse reconhecimento certamente coaduna com os conceitos produzidos pelo conjunto das ciências que compõem a Pedagogia e a reafirmam como as Ciências da Educação, que, por sua vez, pode possibilitar a efetivação dessa finalidade educativa (FREIRE, 1980). Diante das realidades e discussões que se desenvolvem sobre Educação, reconhecemos que, na Escola Pública brasileira, ainda há muito por se fazer para que 
esta se torne efetivamente um modelo democrático (LIBÂNEO, 2006) e adequado na oferta de educação dos alunos que nela estão insertos, buscando refúgio para poderem desenvolver seus potenciais (FREIRE, 1996), mas, diante da realidade brasileira, isso tem se tornado historicamente um ato de resistência (LIBÂNEO, 2006), pois o descaso com a Educação Pública por parte das autoridades, tanto políticas, legislativas como também administrativas, tem distanciado a Escola Pública de desenvolver esse modelo educativo com qualidade (FREIRE, 1980). A Pedagogia e a comunidade escolar têm se empenhado para fazer com que a Escola Pública cumpra seu papel educador (LIBÂNEO, 2006), comprometendo-se com o desenvolvimento global dos alunos e objetivando a autonomia e emancipação tão pretendida (FREIRE, 1996). Sabemos que as dificuldades de implementação de um sistema amplamente democrático e inclusivo de ensino público no Brasil requer ações mais precisas e pontuadas (FREIRE, 1980; BOOTH \& AINSCOW, 2002), pois a diversidade de sujeitos que se encontram no território brasileiro está distante de uma homogeneidade (LIBÂNEO, 2006), sendo que esta diversidade segue desdobrando-se por identidades mais impares e, por vezes, mais múltiplas e complexas (FREIRE, 1996). Desse modo, a Educação Pública e universal brasileira diz respeito às singularidades de cada uma dessas identidades (FREIRE, 1980). Esse trabalho destaca como objeto de investigação a Pessoa com Deficiência (PCD), que, em meio a essa diversidade, encontra-se também como sujeito de direito, sendo constituida pessoa física e, portanto, ativa em todas as esferas no contexto brasileiro, seja ele cultural, étnico, de gênero, religioso, político, ou de qualquer outra condição (LIBÂNEO, 2006). Essas pessoas também precisam ser incluídas no sistema educacional (BRASIL, 1996), que, por sua vez, deve estar preparado para atender à PCD e oferecê-la acesso a esse modelo de educação e desenvolvimento (LIBÂNEO, 2006) como faz com as demais pessoas que não apresentam qualquer deficiência.

Pesquisa : caminhos metodológicos: Para desenvolvermos as análise e identificarmos quais ações são aplicadas para a inclusão da PCD nos estabelecimentos públicos de ensino (CROCHIK, 2016) e como esse projeto de inclusão desenvolve-se no contexto escolar visando a efetivação da garantia do direito à Educação desses alunos (CROCHIK, 2016; BOOTH\& AINSCOW, 2002), foram coletados dados a partir de pesquisas elaboradas por alunos do curso de Pedagogia da Universidade Federal do Pará (UFPA), campus Belém - Pará, Brasil - no segundo semestre do ano de 2018, entre os meses de agosto e dezembro, sendo estas, uma pesquisa bibliográfica e uma pesquisa de campo. A pesquisa de análise de revisão bibliográfica utilizou pressupostos de autores que tratam do tema Inclusão, destacando Booth \& Ainscow (2002), Crochick (2016) e Mazotta (2005), além de conceitos de outros autores que trabalham com temas ligados à Pedagogia e à Educação. Já na pesquisa de campo utilizou-se o método qualiquantitativo e foi aplicada em oito turmas do $5^{\circ}$ ano das Séries Iniciais do Ensino Fundamental, em seis escolas da rede pública de ensino da região urbana de Belém, capital do Estado do Pará, na região Norte do Brasil. Foram utilizados os seguintes instrumentos: observações in locu em todos os espaços escolares, em especial dentro da sala de aula, para identificar todas as relações dos sujeitos envolvidos no processo educativo da PCD (CROCHIK, 2016), das quais se destacam as ações educativas dos professores e a socialização entre todos os alunos com ou sem deficiência (BOOTH \&
AINSCOW, 2002). A observação em sala de aula tinha que obedecer a dois critérios: o primeiro era ter pelo menos um aluno na condição de PCD no interior da sala de aula; e o segundo era que as observações deveriam ser feitas em turmas do $5^{\circ}$ ano das Séries Iniciais do Ensino Fundamental, por ser um momento de transição para as Séries Finais desta etapa da Educação Básica, pois, se para os alunos sem deficiência esse é um fator que deve ser pensado e cuidadosamente trabalhado devido às mudanças a que eles serão consideravelmente submetidos, compreende-se que a PCD também deve ser reconhecida como estando nessa mesma situação (CROCHIK, 2016), portanto, precisa dos mesmos cuidados educacionais que os alunos sem deficiência (BOOTH \& AINSCOW, 2002). A pesquisa também contou com entrevistas semiestruturadas aplicadas junto aos professores das turmas investigadas e gestores de alguns dos estabelecimentos de ensino pesquisado. Essas entrevistas tinham a pretensão de identificar como esses profissionais compreendem a Educação Inclusiva, quais suas propostas educativas CROCHIK, 2016); BOOTH\& AINSCOW, 2002) e como eles veem o sistema educacional brasileiro caminhar na perspectiva inclusiva (CROCHIK, 2018). Outro instrumento utilizado e que nos permitiu refletir a relação afetiva entre os alunos no interior da sala de aula foi a Escala de Proximidade 1 aplicada entre os alunos (CROCHIK, 2016), que tiveram a intenção de medir o grau de afinidade e de rejeição desses educandos com e sem deficiência. Essa escala é baseada no modelo apresentado pelo pesquisado José Leon Crochik (2016), adaptada para ser usada no desenvolvimento dessa pesquisa. Para Medeiros (2020), a pesquisa deve estar presente na vida do Educador, desde os primeiros momentos do seu processo formativo (BOOTH\& AINSCOW, 2002), pois é ela que ampliará a compreensão sobre diversas realidades que a teoria pressupõe (CROCHIK, 2016). Para o autor, é importante colocarmos em prática a pesquisa sobre as questões educacionais que permeiam a Escola Pública, principalmente as de campo, pois são realizadas in locu e nos permitem conhecer a realidade e o contexto em que se encontram os objetos investigados pelo pesquisador (MEDEIROS, 2020).

Resultados e Discussões: análise de dados: A educação escolar brasileira tem uma história que data de meados do século XVI, ainda com ações realizadas pelos jesuítas, mas se limitava a um público distinto (MAZOTTA, 2005). Já a educação oferecida pela escola pública começou a ser ofertada a partir do século XVIII e sua consolidação desdobrou-se ao longo do tempo (MAZOTTA, 2005), mas foi no século XX, a partir da Constituição Federal de 1988, que passamos a conhecer a estrutura de Escola Pública que possuímos hoje no território brasileiro, assim como as garantias de direito à Educação que foram conquistadas pelos sujeitos que vivem em território nacional nessa nova fase da República (BRASIL, 1988; CROCHIK, 2016). Quando tratamos do direito de todos à Educação, reconhecemos a necessidade e de se organizar uma escola que seja capaz de comportar a diversidade de

\footnotetext{
Essa escala ... teve por base o método sociométrico . . . por meio dela verificamos o grau de preferência/rejeição dos alunos considerados em situação de inclusão em comparação com os demais alunos de sua sala. É constituído de seis questões; metade indica preferência por estar com algum colega em especial, as outras três apontam a rejeição a determinado colega. Para cada aluno, foi calculado um escore pela seguinte fórmula: $\mathrm{I}=(\mathrm{P} / 3 \mathrm{n}-3)$ $\pm(\mathrm{R} / 3 \mathrm{n}-3)$ na qual: I é o índice de proximidade; $\mathrm{P}$ o número de citações de determinado aluno nas questões de 1 a 3 , R o número de citações desse aluno nas questões de 4 a 6 , e n é o número de alunos. A variação do escore foi de $-1 \mathrm{a}+1$, quanto maior o escore, maior foi a aceitação de um aluno por seus colegas e vice-versa. (CROCHIK, 2016, p. 27).
} 
alunos e alunas (CROCHIK, 2016; BOOTH\& AINSCOW, 2002), pois, dentro desse público múltiplo, encontramos ainda os que possuem necessidades ímpares, que ultrapassam a barreira da ideia de identidade única e assumem um caráter identitário diverso (CROCHIK, 2018), impulsionando a escola Pública a dar atenção a essas questões, que devem ser discutidas de forma mais constante, principalmente nos locais onde essas pessoas se encontram, na tentativa de garantir seu direito ao ensino e desenvolvimento (BOOTH \& AINSCOW, 2002). Nesse sentido, encontramos também, em meio a esse universo de sujeitos diversos, àqueles que irão necessitar de ações mais específicas para o aprendizado e desenvolvimento escolar (CROCHIK, 2016), logo, focamos nossa investigação na PCD (MAZOTTA, 2005). Nesta seção, apresentamos alguns dados acerca da pesquisa desenvolvida. Inicialmente, apresentamos os sujeitos que fizeram parte dela, identificados na tabela 1 . De acordo com essa tabela, é possível perceber que a PCD está realmente presente no interior da escola pública e lotada em sala de aula regular (CROCHIK, 2018), o que, para a Educação que se pretende inclusiva, torna-se um fator importante, pois segundo o que se tem preconizado para que se perceba esses alunos incluídos (CROCHIK et al., 2009), o fato dos mesmos estarem em um espaço que seja comum a todos os alunos - e não em um espaço que possa estar provocando a segregação - é crucial (BOOTH \& AINSCOW, 2002). O que se pretende também é que os mesmos possam ter sua aprendizagem e seu desenvolvimento dentro de possibilidades que permitam um resultado positivo (CROCHIK, 2018; MAZOTTA, 2005), tanto para a PCD, como para o aluno ou aluna que não apresenta deficiência, dentro do mesmo espaço educativo, de aprendizagem e socialização (CROCHIK, 2016; BOOTH \& AINSCOW, 2002). desinteresse do Poder Público na efetivação de ações que permitam uma Escola Pública verdadeiramente democrática (CROCHIK, 2016). Assim, a qualidade da educação que é desenvolvida pela escola para essa parcela de diferentes, na maioria das vezes, pode ser comprometida e, por isso, não apresentar os resultados esperados (CROCHIK et al., 2009; BOOTH \& AINSCOW, 2002). Outra questão refere-se ao espaço físico dos ambientes escolares, que, na maioria das escolas, não possui uma estrutura pensada para a PCD e nem ao menos adaptações que seriam significativas (CROCHIK et al., 2009), tanto para a acessibilidade, quanto para a mobilidade, que é essencial para o aprendizado e desenvolvimento desses educandos (MAZOTTA, 2005). Os dados que mostram os recursos, a apresentação do espaço físico, profissional e pedagógico na perspectiva inclusiva para a PCD desenvolver seu aprendizado (BOOTH \& AINSCOW, 2002) encontram-se na tabela 2.

Percebe-se que, para os alunos com deficiência, a acessibilidade já se torna reduzida a quase zero (MAZOTTA, 2005), pois, com exceção da escola 1, a maioria dos estabelecimentos de ensino não possuem sequer rampas, sinalização, portas e banheiros adequados ou pelo menos adaptados e em relação aos professores. Isso se torna um problema ainda maior, pois apenas na escola 5 encontram-se professores auxiliares para ajudar os docentes que possuem PCD em suas turmas, com suas demandas diárias, mas, ainda assim, essa escola não possui recursos essenciais (CROCHIK, 2018), como intérpretes da língua oficial da Pessoa Surda estabelecida na Lei $\mathrm{n}^{\mathrm{o}} 10.436^{2}$, a Língua Brasileira de Sinais (LIBRAS) (BRASIL, 2020), que deve ser utilizado para auxiliar na educação da pessoa surda (BOOTH \& AINSCOW, 2002) e, além disso, também não possui materiais e

Tabela 1. Sujeitos

\begin{tabular}{|c|c|c|c|c|c|}
\hline Escolas Pesquisadas & Turmas & Alunos & Alunos com deficiência (s) & Professores & Diretores \\
\hline ESCOLA 1 & 1A & 12 & 01 & 01 & 01 \\
\cline { 2 - 6 } & 1B & 16 & 09 & 01 & 00 \\
\hline \multirow{2}{*}{ ESCOLA 2 } & 2A & 26 & 02 & 01 & 00 \\
\cline { 2 - 6 } & 2B & 26 & 02 & 01 & 00 \\
\hline ESCOLA 3 & 3A & 23 & 01 & 01 & 00 \\
\hline ESCOLA 4 & 4A & 28 & 02 & 01 & 00 \\
\hline ESCOLA 5 & 5A & 29 & 02 & 01 & 00 \\
\hline ESCOLA 6 & 6A & 26 & 02 & $\mathbf{0 8}$ & 00 \\
\hline T06 & $\mathbf{0 8}$ & $\mathbf{1 8 6}$ & $\mathbf{2 1}$ & & \\
\hline
\end{tabular}

Tabela 2. Recurso inclusivo

\begin{tabular}{|c|c|c|c|c|c|c|c|}
\hline Escola & $\begin{array}{l}\text { Banheiro } \\
\text { Adaptado e com sinalização } \\
\text { em libras e braile }\end{array}$ & $\begin{array}{l}\text { Sala de Atendimento } \\
\text { Educacional } \\
\text { Especializado. (AEE) }\end{array}$ & $\begin{array}{l}\text { Rampa de } \\
\text { acesso. }\end{array}$ & $\begin{array}{l}\text { Portas adaptadas } \\
\text { para cadeira de } \\
\text { rodas }\end{array}$ & $\begin{array}{l}\text { Interprete } \\
\text { de libras }\end{array}$ & $\begin{array}{l}\text { Material } \\
\text { em braile }\end{array}$ & $\begin{array}{l}\text { Professor } \\
\text { auxiliar }\end{array}$ \\
\hline 1 & Sim & Sim & Sim & Parcial & Não & Não & Não \\
\hline 2 & Não & Sim & Não & Não & Não & Não & Não \\
\hline 3 & Não & Sim & Não & Não & Não & Não & Não \\
\hline 4 & Não & Sim & Não & Não & Não & Não & Não \\
\hline 5 & Não & Sim & Não & Não & Não & Não & Sim \\
\hline 6 & Não & Não & Não & Não & Não & Não & Não \\
\hline
\end{tabular}

Nessa perspectiv, porém, as observações em sala de aula evidenciam uma realidade contraditória e resultados não muito satisfatórios (CROCHIK, 2018), pois há uma interação entre a PCD, os demais alunos e os professores, mas esses professores muitas vezes, por estarem sozinhos, não encontram soluções para lidar com determinadas situações (CROCHIK et al., 2009) que envolvem a demanda em sala de aula quando há uma PCD na turma (CROCHIK, 2016; BOOTH \& AINSCOW, 2002), visto que essa situação já reflete o

\footnotetext{
LEI N 10.436, DE 24 DE ABRIL DE 2002. Dispõe sobre a Língua Brasileira de Sinais - Libras e dá outras providências.

Art. $1^{\mathrm{o}}$ É reconhecida como meio legal de comunicação e expressão a Língua Brasileira de Sinais - Libras e outros recursos de expressão a ela associados.

Parágrafo único. Entende-se como Língua Brasileira de Sinais - Libras a forma de comunicação e expressão, em que o sistema linguístico de natureza visual-motora, com estrutura gramatical própria, constituem um sistema linguístico de transmissão de idéias e fatos, oriundos de comunidades de pessoas surdas do Brasil (BRASIL, 2002).
} 
profissionais para fazer leitura em braile $e^{3}$ para a educação e desenvolvimento da Pessoa com Deficiência Visual (MAZOTTA, 2005). Dentre outras situações presenciadas, existe um aspecto positivo: mesmo com algumas situações não muito favoráveis (BOOTH \& AINSCOW, 2002), como afalta de material específico para o desenvolvimento da aprendizagem do aluno com Deficiência Intelectual, de alunos com sindromes e transtornos como o Transtorno do Espectro Autista (TEA) e de crianças com deficiências cognitivas diversas (BOOTH \& AINSCOW, 2002; MAZOTTA, 2005), as escolas apresentam salas de Atendimento Educacional Especializado (AEE) e profissionais altamente dedicados no auxílio dos alunos no contra turno (CROCHIK et al., 2009), desdobrando-se na tentativa se sanar muitas dessas dificuldades e objetivando apresentar resultados positivos no desenvolvimento das PCD (BOOTH \& AINSCOW, 2002). Para o diretor da escola 1, a situação de inclusão na Escola Pública reverbera explicitamente a incapacidade do Poder Publico em desenvolver políticas educacionais, que busquem solucionar questões essencialmente importantes nesses espaços (CROCHIK, 2018) para que essa se torne minimamente inclusiva (BOOTH \& AINSCOW, 2002). Assim, o diretor declara que:

Nós temos alunos em situação de inclusão, quer dizer nós temos a necessidade de praticar, de ter práticas inclusivas, mas isso não significa que o nosso currículo, nem tampouco nossos espaços, os nossos tempos sejam organizados nessa lógica. e isso se dá em função da própria organização do sistema. Quer dizer nós não somos na sua essência uma escola inclusiva. . . Nós recebemos alunos dentro da lógica da política da inclusão, e . . . desenvolvemos determinadas práticas inclusivas, mas nós não temos um perfil de uma instituição inclusiva. E aí que tá o grande nó. (Diretor da Escola 1).

Outros dados que achamos importante destacar são os que estão relacionados ao quantitativo e ao percentual dos alunos com e sem deficiência no interior das salas de aula, onde percebemos a PCD em um quantitativo bastante volumoso e um percentual que mostra que esses sujeitos estão presentes (CROCHIK, 2016), ocupando um espaço consideravelmente expressivo dentro da sala de aula (BOOTH \& AINSCOW, 2002) das Escolas Públicas. Esses dados podem ser identificados na tabela 3.

\section{Tabela 3. Quantitativo/percentual de alunos}

\begin{tabular}{|c|c|c|}
\hline \\
\hline \multicolumn{3}{|c|}{ 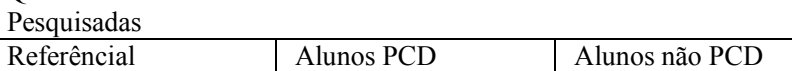 } \\
\hline Quantitativo & 21 & 186 \\
\hline Percentual & $11 \%$ & $89 \%$ \\
\hline
\end{tabular}

A escola 1 é tida como referência no atendimento à $\mathrm{PCD}$ na região urbana de Belém dentro das escolas pesquisadas devido a mesma receber a matrícula de um quantitativo de alunos bastante extenso, como se pôde perceber durante a pesquisa e as observações, mas, embora essa escola consiga garantir a matrícula da PCD e desenvolva ações para tentar tornar a escola minimamente inclusiva (CROCHIK, 2016), não está devidamente organizada pelo sistema educacional para

\footnotetext{
Diz-se de ou sistema de escrita e impressão para cegos, criado pelo francês Louis Braille (1809-1952), que usa caracteres constituídos por pontos em relevo, para representar as diversas letras do alfabeto, os sinais de pontuação e os algarismos; anagliptografia (BRAILLE, 2015).
}

adquirir a identidade de escola inclusiva (BOOTH \& AINSCOW, 2002; CROCHIK, 2018; MAZOTTA, 2005). Sobre isso, o diretor da escola 1 enfatiza:

. . . Predominantemente, são alunos que no caso possuem deficiência auditiva . . pra você ter uma ideia são 80 alunos então esse é um número bastante considerável se você levar em conta o universo da do total de alunos que nós atendemos que é aproximadamente 700 alunos. Então isso faz com que se tenha uma percepção de que existe uma referência do atendimento, mas quando se fala em referência do atendimento isso não significa necessariamente que se tenha um trabalho que seja um trabalho de referência. o que existe na verdade é um atendimento inclusivo, no caso esses alunos, eles têm um atendimento por parte dos profissionais, que são os profissionais de inclusão, eles têm o que a gente chama de atendimento individualizado, eles têm aquela questão, por exemplo, do atendimento que é feito junto até mesmo aos familiares, que precisam de orientações, com relação à informações, com relações ao acolhimento, ao cuidado, etc., mas no aspecto pedagógico ainda existem algumas lacunas que ainda não se conseguiu superar, agora essas lacunas elas acontecem não necessariamente pela falta de vontade do grupo nem tampouco por vontade da gestão da escola ela acontece por conta de uma questão que é que tem haver com o ordenamento do nosso sistema ... (Diretor da Escola 1).

A falta de investimentos no Sistema Público de Ensino (MAZOTTA, 2005) também é denunciada tanto na fala do diretor como na fala de professores e professoras da escola 1, porém, segundo a professora da turma $1 \mathrm{~A}$, que diz contar com a ajuda da experiência há anos adquirida, quando perguntado se ela encontra dificuldades para desenvolver seu trabalho junto aos alunos PCD - que contabilizavam 12 no início do ano letivo, mas, devido à evasão, ao final do ano, contabilizouse 9 alunos - a professora declara que mesmo com as dificuldades encontradas, ela busca desenvolver ações que ao menos minimize as situações desfavoráveis encontradas (BOOTH \& AINSCOW, 2002; CROCHIK, 2016; MAZOTTA, 2005) e que pôr em prática essas ações traz um diferencial para a educação dos alunos PCD. Segundo a professora:

. . . Eu não me deparo assim com uma certa dificuldade por conta da experiência que eu tenho profissional, entendeu? Então essa questão . . . mesmo que você não saiba como lidar, mas que você busque alternativas, que você estude, que você faça pesquisas entendeu? Dá pra complementar . . . eu penso dessa forma, que você tem que distribuir o seu tempo entre eles né? Eu tenho aqui uma diversidade bem extensa. Eu tenho dois síndrome de down, tinha quatro, dois pararam de frequentar, mas tenho dois syndrome de down, tenho um autista . . . tenho três com deficit cognitivo, tenho uma que tem problema na audição, aliás na fala e no sistema nervoso. E pois é! Então, o que é que eu faço? Eu trabalho! (Professora da turma 1A).

Embora sua fala demonstre uma certa positividade, há nas turmas a presença de PCD em uma quantidade muito superior ao que a legislação determina e ao que autores que são autoridades no assunto recomendam - para eles, há a necessidade de professores auxiliares e cuidadores presentes 
nessa situação - (CROCHIK et al., 2009; BOOTH \& AINSCOW, 2002), assim, compreende-se que a educação e o desenvolvimento da PCD nessas condições podem ser seriamente comprometidas (BOOTH \& AINSCOW, 2002; CROCHIK et al., 2009; MAZOTTA, 2005). Um professor da mesma escola, lotado na turma $1 \mathrm{~B}$, onde se encontra uma aluna surda, também fez declarações bastante otimistas em relação à realidade em que se encontram as PCD (BOOTH \& AINSCOW, 2002) na referida escola. Ao dialogar sobre essa situação, o mesmo comenta:

Então a gente tem apoio de grupo de professores que dão assistência para a gente, que vai levando de acordo com algumas informações que entendo de libras, de expressões faciais ou mesmo através de uma linguagem mais adequada para eles, ou o vídeo, enfim, todos os recursos que a gente possa disponibilizar. . . porque eu acho que, como disse no início, a sociedade é um todo e não uma parte, então a escola tem que ter essa preparação e obrigação de trazê-los e com isso a gente também estar preparado para recebê-los e atuar como se fosse um aluno "normal, dito normal né?", a escola tem que ter essa dinâmica, e aí buscar todos os recursos necessários pra isso (Professor da turma 1B).

Se compararmos a fala da professora da turma $1 \mathrm{~A}$ com a do professor da turma $1 \mathrm{~B}$, entendemos que há nesses profissionais a disposição para se colocar em prática, ações para tornar a escola inclusiva (BOOTH \& AINSCOW, 2002), porém, quando o relato do diretor é colocado em pauta, evidencia-se que existe realmente a questão do compromisso profissional desses educadores (CROCHIK, 2018), mas ainda assim, as falhas do sistema educacional são visíveis e encontram-se latentes (CROCHIK et al., 2009; MAZOTTA, 2005), fazendo com que o reflexo desses desacertos do Poder Público reduza a possibilidade da Escola Pública tornar-se um modelo de inclusão para a PCD (CROCHIK, 2016; BOOTH \& AINSCOW, 2002). Diante do exposto, percebe-se que essa Educação Pública é um exemplo visível de resistência diante do descaso narrado (CROCHIK et al., 2009; MAZOTTA, 2005). Isso pode ser observado na fala do diretor da escola 1 , no momento em que o mesmo relata:

. Eu tô conversando aqui com vocês, mas eu to muito focado na lógica dos deficientes auditivos, mas pense nos alunos que tem condutas típicas, alunos que tem espectro autistas, alunos que tem síndrome de down, alunos que tem déficit cognitivo, dificuldades de aprendizagem, enfim! Coloca tudo isso dentro de um contexto situacional que é um contexto de inclusão. Você vai ter como resultados o que? Lacunas enormes, enormes! Aí uma coisa que chama, por exemplo, muito atenção, é que uma grande parte desses alunos, isso eu acho que vocês observaram não sei se vocês observaram grande parte desses alunos, os pais ficam aqui, não são muitos, mas tem uns que ficam aqui na escola acompanhando os filhos e tal... quer dizer isso é uma forma também de amenizar o impacto, porque não raro esse responsável ele sinaliza: - olha tal coisa assim, o aluno não conseguiu perceber, ele não tá conseguindo aprender, entendeu? Aí quer dizer no meu ver nos acabamos fazendo uma prática inclusiva que é, na verdade, uma prática paliativa. Ela não é, no meu entendimento, não é uma prática inclusiva em toda a sua extensão . . . (Diretor da escola 1)
Partindo das observações desenvolvidas no interior da sala de aula, traçamos também um quadro de interação que mostra que a PCD consegue interagir normalmente com os alunos sem deficiência e vice-versa (CROCHIK, 2016; BOOTH \& AINSCOW, 2002). Isso mostra que esses sujeitos estão abertos a socialização, algo que é recorrente e faz parte de faixa etária desses indivíduos (CROCHIK, 2018). A interação ocorreu em todas as escolas pesquisadas, como mostra a tabela 4 .

Tabela 4. Interação entre os alunos em sala de aula

\begin{tabular}{|c|c|c|c|c|}
\hline Escola & Turmas & $\begin{array}{c}\text { Interação } \\
\text { Entre os } \\
\text { Alunos PCD } \\
\text { ou Não }\end{array}$ & $\begin{array}{c}\text { Quantitativo de } \\
\text { Alunos que } \\
\text { Interagem com as } \\
\text { PCD }\end{array}$ & $\begin{array}{c}\text { Percentual de } \\
\text { Interação }\end{array}$ \\
\hline \multirow{2}{*}{1} & 1A & Sim & 11 & $100 \%$ \\
\cline { 2 - 5 } & 1B & Sim & 7 & $100 \%$ \\
\hline 2 & 2A & Sim & 24 & $100 \%$ \\
\cline { 2 - 5 } & 2B & Sim & 24 & $100 \%$ \\
\hline 3 & 3A & Sim & 22 & $100 \%$ \\
\hline 4 & 4A & Sim & 26 & $100 \%$ \\
\hline 5 & 5A & Sim & 27 & $100 \%$ \\
\hline 6 & 6A & Sim & 24 & $100 \%$ \\
\hline
\end{tabular}

Foi identificado que todos os alunos interagem num percentual de cem por cento, porém, dentro dessas relações em sala de aula, isso não significa que há afinidade total entre os alunos com e sem deficiência (CROCHIK, 2016; BOOTH \& AINSCOW, 2002), nem tão pouco essa interação demonstra que há rejeição entre os alunos PCD e os alunos sem deficiência (CROCHIK, 2016). Mesmo havendo um percentual total de interação, não se identifica que os alunos sem deficiência desenvolvam afinidades ou mesmo desconforto quanto a esses sujeitos em sala de aula (CROCHIK, 2018) e, para compreendermos essas relações, por fim, apresentamos na tabela 5 os dados acerca dos resultados da Escala de Proximidade entre alunos com deficiência ou não. Como podemos perceber, a partir do levantamento dos dados, que os educadores desenvolvem, além da interação, cuidados diferenciados (CROCHIK, 2016; BOOTH\& AINSCOW, 2002), mas as PCD ainda não estão incluídas como sujeitos que têm suas relações equiparadas aos demais alunos sem deficiência (CROCHIK, 2018; MAZOTTA, 2005).

Tabela 5. Índice de proximidade/rejeição com base na Escala de Proximidade

\begin{tabular}{|c|c|c|c|}
\hline Turma & Indicação & Índice de proximidade & Índice de rejeição \\
\hline 1A & Aluno 1A & $0,06 \%$ & $0 \%$ \\
\hline 2A & Vários & Sem informações & Sem informações \\
\hline \multirow{2}{*}{ 1B } & Aluno 1B/1 & $0 \%$ & $0 \%$ \\
\cline { 2 - 4 } & Aluno 1B/2 & $0 \%$ & $0 \%$ \\
\hline \multirow{2}{*}{ 2B } & Aluno 2B/1 & $0 \%$ & $0 \%$ \\
\cline { 2 - 4 } & Aluno 2B/2 & $0 \%$ & $0 \%$ \\
\hline 1C & Aluno 1C & $0 \%$ & $0 \%$ \\
\hline 1D & Aluno 1D & $0 \%$ & $-1,30 \%$ \\
\cline { 2 - 4 } & Aluno 2D & $0 \%$ & $0 \%$ \\
\hline \multirow{2}{*}{ 1E } & Aluno 1E & $0 \%$ & $0 \%$ \\
\cline { 2 - 4 } & Aluno 2 E & $0 \%$ & $0 \%$ \\
\hline \multirow{2}{*}{ 1F } & Aluno 1F & $0 \%$ & $0 \%$ \\
\cline { 2 - 4 } & Aluno 2F & $0 \%$ & $0 \%$ \\
\hline
\end{tabular}

A tabela 5 mostra que não há afetividade manifesta por esses alunos nem de forma positiva e nem ao menos negativa entre os sem deficiência e os alunos PCD (CROCHIK, 2016), e, em alguns casos, o percentual negativo identifica que os sem deficiência preferem desenvolver suas relações afetivas entre si, descartando possibilidades em relação à $\mathrm{PCD}$ (CROCHIK, 2018; BOOTH \& AINSCOW, 2002), esta, embora esteja 
presente no interior da sala de aula das Escolas Públicas brasileiras como sujeito detentor do direito à educação, ainda não se encontra incluída nos processos educativos dessa escola como um aluno ou aluna igual (BOOTH \& AINSCOW, 2002; CROCHIK et al., 2009; MAZOTTA, 2005). São pessoas invisíveis nessas relações por apresentarem diferenças ocasionadas por alguma deficiência (CROCHIK, 2016), situação comum nas escolas pesquisadas, o que reafirma que, mesmo sendo um espaço democrático, essa Escola Pública ainda trata o diferente de forma desigual (CROCHIK, 2018; BOOTH \& AINSCOW, 2002) e por diversas situações, em consequência da falta de ações essencialmente necessárias (MAZOTTA, 2005) para o cumprimento desse papel de Escola Pública, universal, democrática e com um potencial para a educação e o desenvolvimento que se mostrem eficazes em um parâmetro global de todos os aluno com e sem deficiencia (BOOTH\& AINSCOW, 2002). Embora saibamos que a inclusão não é possível em sua totalidade (CROCHIK, 2016), ações inclusivas possibilitam que a Escola se torne mais humana e mais democrática (CROCHIK, 2016; BOOTH \& AINSCOW, 2002, MAZOTTA, 2005).

Educação Inclusãoe Legislação: o direito da PCD ao ensino público: A Educação é um fenômeno presente em toda e qualquer sociedade, mesmo que em muitas delas existam sistemas educacionais em modelos diversificados, não há meios de se organizar uma sociedade sem educação (CROCHIK et al., 2009). Apesar dessas variações a Educação Pública que deve ser promovida pelo Estado, já se encontra como um marco desde a Declaração Universal dos Direitos Humanos (DUDH) instituida pela Organização das Nações Unidas (ONU), entidade da qual o Brasil é membro fundador desde o ano de 1945.

\section{Declaração Universal dos Direitos Humanos: Artigo 26.}

- Todo ser humano tem direito à educação. A educação será gratuita, pelo menos nos graus elementares e fundamentais. A educação elementar será obrigatória. A educação técnico-profissional será acessível a todos, bem como a instrução superior, esta baseada no mérito.

- A educação será orientada no sentido do pleno desenvolvimento da personalidade humana e do fortalecimento do respeito pelos direitos humanos e pelas liberdades fundamentais. A educação promoverá a compreensão, a tolerância e a amizade entre as nações e grupos raciais ou religiosos, e deve desenvolver as atividades da ONU em prol da manutenção da paz.

- Os pais têm prioridade de direito na escolha do tipo de educação que será fornecida a seus filhos. (Assembleia Geral da ONU, 1948).

Historicamente, o Brasil tem buscado cumprir, dentro dessas perspectivas, a efetivação de garantia dos direitos a todos os comtemplados pelos mesmos (MAZOTTA, 2005). Essa busca, contudo, tem ampliado o arcabuço de leis que organizam os direitos dessas pessoas, mas esses direitos muitas vezes não recebem atenção política necessária para sua implementação (BOOTH \& AINSCOW, 2002), pois carecem da disponibilização de recursos, que não se concretizam, fazendo com que a Escola Pública passe a exercer uma posição de resistência dentro do sistema (CROCHIK, 2016; MAZOTTA, 2005). Para o Estado brasileiro, a educação passa a ser um direito constituído, mas duramente conquistado, e sua efetivação deveria materializar-se a partir da Escola Pública
(CROCHIK et al., 2009), porém, entendemos que, para garantir o direito de todos à Educação, devemos levar em conta que, dentro dessa totalidade de sujeitos que são amparados por lei, existem diferenças que precisam ser consideradas (BOOTH \& AINSCOW, 2002; CROCHIK, 2016; MAZOTTA, 2005), pois esse todo no contexto das diversas identidades brasileiras não se determina por sujeitos iguais (CROCHIK, 2016), esses, por sua vez, estão envolvidos por singularidades que os apresentam como diferentes dentro dessa diversidade (BOOTH\& AINSCOW, 2002) e que, por vezes, precisam de um projeto educativo diferenciado para atender a essas especifidades educativas, como é o caso da PCD (MAZOTTA, 2005).

O sistema educacional público no Brasil estrutura-se a partir de uma legislação que culmina com o estabelecimento da instituição de ensino que conhecemos por Escola (BRASIL, 1988). A lei no 4.024, de 1961 - que estabelece a Lei de Diretrizes e Bases da Educação Nacional (LDBEN) pode ser entendida como a detentora da principal orientação para a organização do Sistema de Educação brasileiro. Essa legislação não abrange apenas a Escola Pública, mas também a rede privada de ensino do país (BRASIL, 1996). Ainda de acordo com a legislação brasileira, a escola de domínio público deve ser a responsável por acolher todos os sujeitos que dela quiserem fazer uso e que nela vão ser escolarizados (BOOTH \& AINSCOW, 2002; BRASIL, 1996; CROCHIK, 2016), por isso, para que todos sejam contemplados com esse ensino público, ele é oferecido gratuitamente, para que a população realmente tenham acesso a esse modelo educacional (BRASIL, 1996), como já determinado desde a DHDH. Quando tratamos de ações relacionadas à garantia de direitos e pretendemos que o efeito desses direitos tenham um reflexo verdadeiramente convergente para todos os sujeitos (BOOTH\& AINSCOW, 2002; CROCHIK, 2016) - e quando focamos na Educação, principalmente da Escola Pública -, identificamos a necessidade de ações que busquem trabalhar de uma forma equânime (BRASIL, 1996), visando a possibilidade de equiparar esses sujeitos e minimizar os efeitos negativos da desigualdade (CROCHIK, 2016) enfrentada pelos que historicamente encontram-se afetados pelo sistema que possibilitou tais desigualdades (CROCHIK, 2016; MAZOTTA, 2005).

Art. 205. A educação, direito de todos e dever do Estado e da família, será promovida e incentivada com a colaboração da sociedade, visando ao pleno desenvolvimento da pessoa, seu preparo para o exercício da cidadania e sua qualificação para o trabalho (BRASIL, 2019).

Também preconizada no artigo $210^{4}$ da Constituição da República Federativa do Brasil de 1988, para que fosse garantida a educação com os saberes mínimos que devem ser ensinados na Escola Pública brasileira (BRASIL, 1988), a Base Nacional Comum Curricular (BNCC), que passou a direcionar o currículo no território nacional, reafirma o que se tem compreendido sobre a necessidade de estabelecer condições específicas na Educação Escolar para que ela se torne inclusiva (BOOTH \& AINSCOW, 2002), fazendo essa referência sobre si, afirmando a orientação do documento:

\footnotetext{
${ }^{4}$ Art. 210. Serão fixados conteúdos mínimos para o ensino fundamental, de maneira a assegurar formação básica comum e respeito aos valores culturais e artísticos, nacionais e regionais. (BRASIL, 1988).
} 
Este documento normativo aplica-se exclusivamente à educação escolar, tal como a define o $\S 1^{\circ}$ do Artigo $1^{\circ}$ da Lei de Diretrizes e Bases da Educação Nacional (LDB, Lei $\left.\mathrm{n}^{\mathrm{o}} 9.394 / 1996\right)^{5}$, e está orientado pelos princípios éticos, políticos e estéticos que visam à formação humana integral e à construção de uma sociedade justa, democrática e inclusiva, como fundamentado nas Diretrizes Curriculares Nacionais da Educação Básica (DCN) ${ }^{6}$. (BRASIL, 2017, p. 7).

A BNCC, ainda, traz declarações que possibilitam a percepção de que a Educação dos sujeitos deve levar em conta algumas necessidades e pontos específicos para que ela se torne uma escola democrática e inclusiva (BOOTH \& AINSCOW, 2002; BRASIL, 1996; CROCHIK, 2016).

Reconhece, assim, que a Educação Básica deve visar à formação e ao desenvolvimento humano global, o que implica compreender a complexidade e a não linearidade desse desenvolvimento, rompendo com visões reducionistas que privilegiam ou a dimensão intelectual (cognitiva) ou a dimensão afetiva. Significa, ainda, assumir uma visão plural, singular e integral da criança, do adolescente, do jovem e do adulto - considerando-os como sujeitos de aprendizagem - e promover uma educação voltada ao seu acolhimento, reconhecimento e desenvolvimento pleno, nas suas singularidades e diversidades. Além disso, a escola, como espaço de aprendizagem e de democracia inclusiva, deve se fortalecer na prática coercitiva de não discriminação, não preconceito e respeito às diferenças e diversidades (BRASIL, 2017, p.14).

Também assegurada pelo Estatuto da Criança $e$ do Adolescente (ECA), o documento reconhece que a Educação da PCD precisa, além da inclusão desta no sistema público educacional, de ações educativas distintas (BOOTH \& AINSCOW, BRASIL, 1990 2002; MAZOTTA, 2005), paraque tenham seu direito garantido pelo Estado brasileiro (CROCHIK, 2016), ressalvando que a educação dos mesmos necessitam de um atendimento especializado (BOOTH\& AINSCOW, 2002; BRASIL, 1990), como observamos nas determinações legais desse Estatuto:

Capítulo I - Do Direito à Vida e à Saúde Art. 11.

... (Redação dada pela Lei $\left.n^{\circ} 11.185 / 2005\right) \S 1^{\circ}$ A criança e o adolescente portadores de deficiência receberão atendimento especializado.

Capítulo IV - Do Direito à Educação, à Cultura, ao Esporte e ao Lazer Art.54. É dever do Estado assegurar à criança e ao adolescente: III - atendimento educacional especializado aos portadores de deficiência,

\footnotetext{
${ }^{5}$ BRASIL. Lei no 9.394, de 20 de dezembro de 1996. Estabelece as Diretrizes e Bases da Educação Nacional. Diário Oficial da União, Brasília, 23 de dezembro de 1996. Disponível em:<http://www.planalto.gov.br/ ccivil_03/ leis/19394.htm> Acesso em: 23 mar. 2017. (Nota de rodapé do texto original)

62 BRASIL. Ministério da Educação; Secretaria de Educação Básica; Secretaria de Educação Continuada, Alfabetização, Diversidade e Inclusão; Secretaria de Educação Profissional e Tecnológica. Conselho Nacional de Educação; Câmara de Educação Básica. Diretrizes Curriculares Nacionais da Educação Básica. Brasília: MEC; SEB; DICEI, 2013.Disponível em: $<$ http://portal.mec.gov.br/index.php?option=com.docman\&view=downl oad\&alias=13448-diretrizes-curriculares-nacionais-2013-

pdf\&ltemid $=30192>$. Acesso em: 16 out. 2017. (Nota de rodapé do texto original)
}

preferencialmente na rede regular de ensino; . . . (BRASIL, 1990).

Outro dispositivo que visa dinamizar a garantia de direitos da PCD, é a Lei ${ }^{\circ} 13.146^{7}$, que institui o Estatuto da Pessoa Com Deficiência (EPCD). Essa Lei especifica como deve se determinar a Educação dirigida a esses sujeitos:

Art. 27. A educação constitui direito da pessoa com deficiência, assegurados pelo sistema educacional inclusivo em todos os níveis e aprendizado ao longo de toda a vida, de forma a alcançar o máximo desenvolvimento possível de seus talentos e habilidades físicas, sensoriais, intelectuais e sociais, segundo suas características, interesses e necessidades de aprendizagem.

Parágrafo único. É dever do Estado, da família, da comunidade escolar e da sociedade assegurar educação de qualidade à pessoa com deficiência, colocando-a a salvo de toda forma de violência, negligência e discriminação (BRASIL, 2015). Outras legislações foram criadas ao longo do tempo, na tentativa de fazer com que o sistema orgânico da Educação brasileira pudesse dar conta de situações diversas sobre a questão da inclusão (CROCHIK, 2016) e, dentre essas questões,alinham-se os direitos do PCD (MAZOTTA, 2005). Percebemos que existe um gama de aparatos legislativos para que o direito à Educação da PCD seja efetivado a partir de uma Escola Pública que esteja comprometida com o processo de inclusão (CROCHIK, 2016) desses personagens que são, na verdade, os protagonistas dessas legislações específicas (BOOTH \& AINSCOW, 2002; MAZOTTA, 2005), mas entendemos que o sistema educativo proposto pela Escola Pública brasileira não tem avançado nesse sentido (CROCHIK, 2016). Isso não significa que a comunidade escolar não esteja atenta para essa demanda, mas o sistema político - de onde deve partir as principais ações visando minimizar as dificuldades encontradas (BOOTH \& AINSCOW, 2002), tanto pela escola quanto para garantia de direitos à Educação da PCD - tem se mostrado ausente nesse sentido (MAZOTTA, 2005), isso é perceptível nos estabelecimentos escolares pesquisados e torna-se parte latente no discurso dos profissionais da educação que desenvolvem suas atividades docentes e administrativas nesses espaços.

Finalizando: Ao direcionarmos nosso olhar para a Pessoa Com Deficiencia como sujeito de direitos e os reconhecemos como protagonistas, destacando a Educação dessas pessoas e sua efetivação a partir da Escola Pública, percebemos que há um longo caminho a ser percorrido, para a inclusão dessa PCD na Escola Pública brasileira, principalmente nas que se encontram na região Norte do Brasil - que apresenta um índice de pobreza dos mais acentuados do país na atualidade. A escola inclusiva ainda é uma realidade que se encontra distinta, mais potencialmente promissora, embora se tenha a compreensão de que a inclusão dos sujeitos que hoje encontram-se excluídos do sistema educacional público de ensino não seja uma realidade que em um momento irá atingir um grau de totalidade e plenitude. A escola pública, mesmo encontrando dificuldade de manutenção pelo Estado, busca, através de seu papel de democratização do ensino, desenvolver

\footnotetext{
${ }^{7}$ Lei Federal $n^{\mathrm{o}} 13.146$, de 06 de Julho de 2015. Institui a Lei Brasileira de Inclusão da Pessoa com Deficiência (Estatuto da Pessoa com Deficiência PCD).
} 
meios para que os impactos de uma possível falha na inclusão da PCD no estabelecimento public de ensino seja sanada, visando efetivar a garantia de direitos à educação e desenvolvimento desses sujeitos. As pesquisas desenvolvidas nesse sentido ganham foco para a compreensão dessas falhas, pois, a partir da identificação das mesmas, é possível corrigir eventuais dificuldades de implementação de um sistema de ensino adequado para a educação da PCD nas escolas. Essa não é uma tarefa simples, visto que a Escola Pública Brasileira historicamente enfrenta dificuldades de aperfeiçoamento devido a questões de vários segmentos, onde as de ordem política destacam-se no que diz respeito à implementação de ações voltadas para o desenvolvimento tanto estrutural, quanto profissional dos mecanismos que asseguram o funcionamento das instituições públicas de ensino no país.

\section{REFERÊNCIAS}

Assembléia geral Da Onu, 1948. Declaração Universal dos Direitos Humanos. Paris,

Booth, T; \& Ainscow, M. 2002. Index para a inclusão: desenvolvendo a aprendizagem e a participação na escola. (A. B. da Costa \& J. V. Pinto, Trad.). Sintra: Cidadãos do Mundo.

Braille. Michaelis, 2015. Disponível em: https://michaelis. uol.com.br/moderno-portugues/busca/portugues-brasileiro/ braille/. Acesso em: 20 set. 2019.

Brasil, 1988. Constituição da República Federativa do Brasil: texto constitucional promulgado em 5 de outubro de 1988, com as alterações determinadas pelas Emendas Constitucionais de Revisão nos 1 a 6/94, pelas Emendas Constitucionais nos 1/92 a 91/2016 e pelo Decreto Legislativo no 186/2008. Brasília: Senado Federal, Coordenação de Edições Técnicas, 2016.

Brasil, 1990. Lei n. 8.069, de 13 de julho de 1990. Dispõe sobre o Estatuto da Criança e do Adolescente e dá outras providências. Disponível em: http://www.planalto.gov.br/ccivil_03/ LEIS/L8069.htm\#art266. Acesso em: 05 set. 2019.
Brasil, 1996. Ministério da Educação. Lei n ${ }^{\circ}$ 9.394, de 20 de dezembro de 1996. Estabelece as diretrizes e bases da educação nacional. Disponível em: <http://portal.mec.gov.br/ seed/arquivos/pdf/tvescola/leis/lein9394.pdf >. Acesso em: 20 set. 2019.

Brasil, 2015. Lei n. 13.146, de 6 de julho de 2015. Institui aLei Brasileira de Inclusão da pessoa com Deficiência (Estatuto da Pessoa com Deficiência). Disponível em: http:// www.planalto.gov.br/ccivil_03/_ato2015-2018/2015/ lei/113146.htm. Acesso em: 05 set. 2019.

Brasil, 2020. Lei $\mathrm{n}^{\mathrm{o}} 10.436$, de 24 de abril de 2020. Dispõe sobre a Língua Brasileira de Sinais - Libras e dá outras providências. Disponível em: http://www.planalto.gov.br/ccivil_03/leis/ 2002/110436.htm. Acesso em: 20set. 2019.

Crochik, J. L et al. 2009. Atitudes de Professores em Relação à Educação Inclusiva. Psicologia Ciência e Profissão, 29(1), 4059.

Crochik, J. L. (Org.). 2016. Educação inclusiva: algumas pesquisas. Novas Edições Acadêmicas, Saarbrücken.

Crochik, J. L. 2018. Preconceito em relação aos 'incluídos' na educação inclusiva. São Paulo: IPUSP.

Freire, P. 1996. Pedagogia da autonomia: saberes necessários a prática educativa. (35. ed.). São Paulo: Paz e Terra.

Libâneo, J. C. 2006. Diretrizes curriculares da Pedagogia: um adeus à Pedagogia e aos pedagogos? Recuperado de: http://www.ced.ufsc.br/nova/Textos/JoseCarlosLibaneo.htm.

Mazotta, M. J. S. 2005. Educação especial no Brasil: história e políticas públicas. (5. ed.). São Paulo: Cortez.

Medeiros, L. T. C. 2020. Educação Pública e Inclusão nas Séries Iniciais do Ensino Fundamental: práticas e enfrentamentos nas escolas em Belém (PA). BrazilianJournalofdevelopment, 6(3), 12178-12198. 